\title{
The Pathological Spectrum of Pediatric Kidney Disease: 18-year Experience From a Single Tertiary Care Center in Northern Taiwan
}

\section{Chen-Wei Yen}

Lin-Kou Chang Gung Memorial Hospital

\section{Tai-Di Chen}

Lin-Kou Chang Gung Memorial Hospital

\section{Tzung-Hai Yen}

Lin-Kou Chang Gung Memorial Hospital

Mei-Ching Yu ( $\nabla$ mc.yu@cgmh.org.tw )

Lin-Kou Chang Gung Memorial Hospital

\section{Research Article}

Keywords: Percutaneous renal biopsy, Lupus nephritis, IgA nephropathy, Minimal change disease

Posted Date: January 24th, 2022

DOl: https://doi.org/10.21203/rs.3.rs-1255549/v1

License: @ (i) This work is licensed under a Creative Commons Attribution 4.0 International License. Read Full License 


\section{Abstract}

Background: Glomerular disease is one of major causes leading to chronic kidney disease in children worldwide. The recent publications showed the changing spectrum of glomerular disease in certain countries. Therefore, we aimed to evaluate the histopathological patterns and change of pediatric kidney disease over the past eighteen years in northern Taiwan.

Methods: This was a retrospective chart review study of the pediatric patients ( $\leq 18$ years of age) undergoing percutaneous renal biopsies (PRBs) of native kidneys between January 2002 to July 2020 from a Pediatric Care Center at Chang Gung Memorial Hospital, Taoyuan, Taiwan.

Results: A total of 339 pediatric native PRBs were analyzed in this study. The mean age of the subjects was $13.7 \pm 7.0$ years (184 girls and 155 boys). The most common indications of PRBs included acute nephritic syndrome (55.7\%), idiopathic nephrotic syndrome (22.7\%), persistent asymptomatic hematuria (13.9\%) and unexplained renal failure (7.7\%), respectively. Our study revealed proliferative lupus nephritis $(\mathrm{LN})$, minimal change disease (MCD) related nephrotic syndrome and IgA nephropathy (IgAN) were the most frequent biopsy-proven pediatric glomerular diseases. Furthermore, we also found severe acute post-streptococcal glomerulonephritis (APSGN) was infrequent and even not be recognized after 2010.

Conclusions: Our result disclosed the spectrum of biopsy-proven pediatric kidney disease was not significantly changed over the past two decades in northern Taiwan. LN, MCD and primary IgAN continued to be the most common histopathological diagnosis among Taiwanese children. We speculated multiple environmental and public health polices implemented in Taiwan might partly contribute to this unchanged pathological spectrum of pediatric kidney disease and reduced burden of infection-associated glomerular disease such as APSGN and pneumococcal-induced hemolytic uremic syndrome.

\section{Introduction}

Glomerular disease still remains a major cause of pediatric chronic kidney disease (CKD) across the globe, and particularly predominate in the developing countries such as India, Southeast Asia, Latin America, Caribbean region and Sub-Saharan Africa [1-3]. Overwhelmingly, all forms of glomerulonephritis (GN) have a tendency of rapid progression to end-stage renal disease failure compared with CKD children affected by congenital anomalies of kidney and urinary tract. Substantial studies already disclose diagnosis and outcome of glomerular disease significantly differ between age group (adults and children), sex and race [4,5]. Furthermore, accumulating evidence indicates its multifactorial and heterogenous pathogenic mechanism, displaying the crucial roles of genetics and gene-environment interactions in development and progression of kidney disease [6, 7]. Particularly exposure to environmental risk factors, such as air population, heavy metal and other environmental pollutants (e.g., aristolochic acids, pesticides, phthalates and bisphenol A) and infections, is related to alterations in glomerular disease frequencies [8]. 
Recently, Nie et al. conducted a nationwide survey consisting of 7962 pediatric kidney biopsies from 115 hospitals across China from January 2004 to December 2014 [5]. They found the proportion of membrane nephropathy $(\mathrm{MN})$ increased from 3-7\% during the past 10 years. Another study by Xu et al. also reported a similar increasing trend of $\mathrm{MN}$ among adult population in China. They assumed the changing spectrum of glomerular disease was most likely associated with long-term exposures to air pollution [9]. In Taiwan, over the past decades, growing public awareness of control and prevention of infectious disease and environmental hazards has led to public health promotion. For instance, leaded gasoline was banned since 2000 to reduce environmental exposure to lead [10]. Soon after, aristolochic acid containing Chinese herbal products were also prohibited due to its nephrotoxicity and carcinogenicity [11]. Furthermore, increased immunization coverage after the Taiwan National Health Insurance Program in 1995 is highly effective for reducing the burden of vaccine-preventable infectious diseases.

After these polices, in this 18-year retrospective study, we aimed to estimate the epidemiological profiles and overall changes in biopsy proven pediatric kidney disease over time from a pediatric tertiary care center in northern Taiwan.

\section{Methods}

\section{Participants and study design}

This retrospective chart review study was conducted at Lin-Kou Chang Gung Memorial Hospital in Taoyuan, Taiwan during the period from January 2002 to July 2020. A total of 339 pediatric patients aged between 0 - 18 years (184 girls and 155 boys) undergoing ultrasound-guided percutaneous renal biopsies (PRBs) of native kidneys were enrolled in the study. The frequent indications of PRBs included isolated moderate to severe proteinuria defined by a 24-hour urine protein $>1 \mathrm{~g} /$ day or morning spot urine protein-to-creatinine ratio (UPCR) $>1 \mathrm{~g} / \mathrm{g}$, idiopathic nephrotic syndrome (INS) characterized by nephrotic range proteinuria $>40 \mathrm{mg} / \mathrm{m}^{2} /$ hour or UPCR $>2 \mathrm{~g} / \mathrm{g}$, hypoalbuminemia, hyperlipidemia and edema [12], persistent asymptomatic hematuria with/without proteinuria, unexplained renal impairment and acute nephritis syndrome secondary to autoimmune disorders such as systemic lupus erythematous (SLE) or others. For investigating the epidemiological profiles and overall changes of pediatric kidney biopsies over the past eighteen years, we divided the participants into two groups depending on the date of having biopsy procedure in different consecutive periods, between January 2002 to December 2010 (2002 2010), and between January 2011 to July 2020 (2011 - 2020), respectively. In addition, our study also assessed gender and age differences in kidney disease frequencies during the study period.

\section{Statistical analysis}

The statistical data analysis was conducted by using Statistical Package for Social Sciences, version 26.0 (SPSS Inc., Chicago, Illinois). Categorical variables were compared using the Chi-square tests and continuous variables were compared by t-tests. $P$ value $<0.05$ was considered to be statistically significant. 


\section{Results}

\section{Practice and demographic characteristics of the pediatric patients undergoing PRBs}

As shown in Table 1, the most frequent indication of PRBs was acute nephritis secondary to certain autoimmune disorders (55.7\%), especially SLE (41.0\%). The second most common indication was INS (22.7\%), including $11.8 \%$ of INS children aged $>10$ years, $9.7 \%$ of steroid sensitive NS (SSNS) and only $1.2 \%$ of steroid-resistant NS (SRNS), respectively. Among SSNS cases, PRBs were commonly executed in the affected children presenting frequent relapsing NS (FRNS) (4.1\%), delayed response to steroid or decreased renal function under calcineurin inhibitors (CNIs) such as cyclosporine or tacrolimus (3.2\%) and steroid-dependent NS (SDNS) (2.4\%), respectively. Besides, the other common indications included persistent asymptomatic hematuria with mild proteinuria (10.9\%), persistent isolated microscopic hematuria (3.0\%) and unexplained renal impairment (7.7\%).

Table 1

The common indications of PRBs in our 339 pediatric patients.

\begin{tabular}{|ll|}
\hline Indications & Total, $\mathbf{n}(\%)$ \\
\hline Acute nephritis syndrome & $189(55.7)$ \\
\hline SLE with renal involvement & $139(41.0)$ \\
\hline Related to other disease or medications & $50(14.7)$ \\
\hline Idiopathic nephrotic syndrome (INS) & $77(22.7)$ \\
\hline Steroid-sensitive NS & $33(9.7)$ \\
\hline Delay response to steroid or decreased renal function under CNIS $\left.{ }^{[14,15]}\right]$ & $11(3.2)$ \\
\hline Frequent relapsing NS & $14(4.1)$ \\
\hline Steroid-dependent NS & $8(2.4)$ \\
\hline Children aged > 10 years (16) & $40(11.8)$ \\
\hline Steroid-resistant NS & $4(1.2)$ \\
\hline Persistent asymptomatic hematuria & $47(13.9)$ \\
\hline Concomitant proteinuria & $37(10.9)$ \\
\hline Isolated microscopic hematuria & $10(3.0)$ \\
\hline Unexplained renal impairment & $26(7.7)$ \\
\hline Total & $339(100)$ \\
\hline
\end{tabular}


Table 2 illustrated gender differences in clinical and histopathological manifestations of 339 children and adolescents undergoing PRBs over the period from 2002 to 2020 in our hospital. The mean age at the time of renal biopsy for histological diagnosis was $13.6 \pm 7.0$ years (184 girls aged $15.5 \pm 7.1$ years and 155 boys aged $11.4 \pm 6.1$ years, $P<0.001$ ). Obviously, the age of pediatric patients with kidney disease requiring PRBs was older in girls than in boys regardless of the time periods, from 2002 to 2010 (girls aged $12.9 \pm 6.1$ years $v s$. boys aged $10.6 \pm 4.7$ years, $P=0.034$ ) and from 2011 to 2020 (girls aged $16.6 \pm$ 7.2 years $v s$. boys aged $11.8 \pm 6.7$ years, $P<0.001$ ). This could be the result of a significantly higher prevalence of lupus nephritis $(L N)$ in female pediatric patients $(31.3 \% v s .9 .7 \%, P<0.001)$. According to the International Society of Nephrology and the Renal Pathology Society (ISN/RPS) classification, the most frequent histological subtype was class IV (diffuse proliferative) LN $(16.2 \%$ vs. $6.8 \%, P<0.001)$, followed by class III (focal proliferative) LN $(4.7 \%$ vs. $0.6 \%, P=0.002)$ and class $\mathrm{V}$ (membranous) $\mathrm{LN}$ ( $2.4 \%$ vs. $0.3 \%, P=0.035)$. Furthermore, the female-to-male ratio was approximately $3: 1$ in pediatric lupus with LN. However, a relative predominance of male pediatric patients was observed in other forms of acute nephritis secondary to non-lupus autoimmune kidney disease or medications ( $8.8 \%$ vs. $5.9 \%$, $P=0.014$ ) (Supplementary Table 1). 
Table 2

Gender differences in clinical and histopathological manifestations of 339 biopsied pediatric patients.

Characteristics

Total,

Sex

P-value

$\mathrm{n}=339$

$(100 \%)$
Boys,

$\mathrm{n}=155$

(45.7\%)
Age at the time of renal biopsy (years)

Between 2002 to 2010

Between 2011 to 2020

Clinical manifestations, $\mathrm{n}(\%)$

Nephritis syndrome

Lupus nephritis

ISN/RPS Class I

ISN/RPS Class II

ISN/RPS Class III

ISN/RPS Class IV

ISN/RPS Class V

ISN/RPS Class VI

ISN/RPS Class III + V

ISN/RPS Class IV + V

Related to other diseases or medications

Idiopathic nephrotic syndrome

SSNS
$13.6 \pm 7.0$

$11.8 \pm 5.6$

$14.5 \pm 7.4$

$11.4 \pm 6.1$

Girls,

$\mathrm{n}=184$

(54.3\%)

$15.5 \pm 7.1<$

0.001 *

$12.9 \pm 6.1$

$0.034^{*}$

$10.6 \pm 4.7$

$16.6 \pm 7.2$

$<$

$0.001^{*}$

$189(55.7) \quad 63(18.5)$

$33(9.7)$

$139(41.0)$

$5(1.5)$

12 (3.6)

$18(5.3)$

78 (23)

$9(2.7)$

4 (1.2)

$6(1.8)$

7 (2.1)

50 (14.7)

77 (22.7)

49 (14.4)

$24(7.1)$

$1(0.3)$

30 (8.8)

$33(9.7)$
$126(37.2)$

$<$

$0.001^{*}$

106 (31.3)

$<$

$0.001^{*}$

0.246

4 (1.2)

0.143

9 (2.7)

$0.002^{*}$

$16(4.7)$

$<$

$0.001^{*}$

8 (2.4)

$0.035^{*}$

$3(0.9)$

0.404

5 (1.5)

0.150

6 (1.8)

0.092

$20(5.9)$

$0.014^{*}$

$28(8.3)$

$<$

$0.001^{*}$

$9(2.6)$

$<$

$0.001^{*}$

The comparisons between categorical variables and continuous variables are compared using the Chi-square tests and t-tests, respectively. ${ }^{*} P$ value $<0.05$ is considered to be statistically significant. ${ }^{*}$ Others include thin basement membrane disease, Alport syndrome, C3 glomerulopathy and insufficiency for diagnosis. 


\begin{tabular}{|c|c|c|c|c|}
\hline \multirow[t]{3}{*}{ Characteristics } & \multirow{3}{*}{$\begin{array}{l}\text { Total, } \\
\mathrm{n}=339 \\
(100 \%)\end{array}$} & \multicolumn{2}{|l|}{ Sex } & \multirow[t]{3}{*}{$P$-value } \\
\hline & & \multirow{2}{*}{$\begin{array}{l}\text { Boys, } \\
n=155 \\
(45.7 \%)\end{array}$} & \multirow{2}{*}{$\begin{array}{l}\text { Girls, } \\
\mathrm{n}=184 \\
(54.3 \%)\end{array}$} & \\
\hline & & & & \\
\hline MCD & $23(6.8)$ & $18(5.3)$ & $5(1.5)$ & $0.001^{*}$ \\
\hline FSGS & $6(1.8)$ & $4(1.2)$ & $2(0.6)$ & 0.300 \\
\hline Others & $4(1.2)$ & $2(0.6)$ & $2(0.6)$ & 0.863 \\
\hline Age $>10$ years & $40(11.8)$ & $22(6.5)$ & $18(5.3)$ & 0.211 \\
\hline MCD & $26(7.6)$ & $16(4.7)$ & $10(2.9)$ & 0.093 \\
\hline Others & $14(4.1)$ & $6(1.8)$ & $8(2.4)$ & 0.827 \\
\hline SRNS & $4(1.2)$ & $3(0.9)$ & $1(0.3)$ & 0.238 \\
\hline MCD & $2(0.6)$ & $1(0.3)$ & $1(0.3)$ & 0.903 \\
\hline FSGS & $2(0.6)$ & $2(0.6)$ & $0(0)$ & 0.123 \\
\hline $\begin{array}{l}\text { Persistent asymptomatic hematuria } \pm \\
\text { proteinuria }\end{array}$ & $47(13.9)$ & $28(8.3)$ & $19(5.6)$ & $0.040^{*}$ \\
\hline $\operatorname{IgAN}$ & $34(10)$ & $20(5.9)$ & $14(4.1)$ & 0.053 \\
\hline Others $*$ & $13(3.9)$ & $8(2.4)$ & $5(1.5)$ & 0.244 \\
\hline Unexplained renal impairment & $26(7.7)$ & $15(4.4)$ & $11(3.3)$ & 0.203 \\
\hline \multicolumn{5}{|c|}{$\begin{array}{l}\text { The comparisons between categorical variables and continuous variables are compared using the } \\
\text { Chi-square tests and t-tests, respectively. }{ }^{*} P \text { value }<0.05 \text { is considered to be statistically significant. }{ }^{*} \\
\text { Others include thin basement membrane disease, Alport syndrome, C3 glomerulopathy and } \\
\text { insufficiency for diagnosis. }\end{array}$} \\
\hline
\end{tabular}

On the other hand, boys had a higher rate of INS compared with girls (14.4\% vs. 8.3\%, $P<0.001)$, and the vast majority of cases were SSNS and MCD $(P<0.001)$. Regarding adolescent NS (children aged $>10$ years), our result showed MCD appeared to be the common underlying disease, but there was no statistical difference between boys and girls. Besides, male predominance was also significant in children with persistent hematuria with and without mild proteinuria ( $8.3 \%$ vs. $5.6 \%, P=0.04)$, and half of the affected boys (20/47) were diagnosed of primary IgAN.

\section{Age distribution, histopathologic profiling and changes of pediatric kidney disease}

Table 3 showed the comparisons of histopathological profiles and changes across the two different consecutive periods, from 2002 to 2010 and from 2011 to 2020, respectively, and the age disparity in 
disease patterns among the two groups, children aged $<12$ year and adolescents aged $12-18$ years, respectively. Our result uncovered that pediatric $L N, M C D$ and IgAN were the most common histopathological diagnosis of pediatric kidney disease over the past two decades. Obviously, LN was more prevalent in female lupus pediatric patients and older age group of adolescents (12-18 years old). We also found a rising tendency of pediatric LN, especially class IV LN, over time across the study period. However, this change was not significant statistically (Supplementary Figure 1). The age disparity and the changing pathological spectrum of pediatric kidney disease including MCD, IgAN, focal segmental glomerulosclerosis (FSGS), tubulointerstitial disease (TID), Henoch-Schönlein purpura nephritis (HSPN), thrombotic microangiopathy (TMA), anti-neutrophil cytoplasmic antibody (ANCA) associated GN, and hereditary disease were also insignificant. Besides, our study showed severe APSGN was rare and infrequent, particularly for adolescent patients and this bacterial infection related GN was even not be recognized after 2010 . 
Table 3

The comparison of age disparity between the two groups, aged $<12$ years and 12-18 years, in the histopathological profiles among the two consecutive periods, from 2002 to 2010 and from 2011 to 2020.

\begin{tabular}{|c|c|c|c|c|c|c|}
\hline \multirow[t]{2}{*}{ Renal pathology (n) } & \multicolumn{3}{|c|}{ < 12 years old, $n$ (\%) } & \multicolumn{3}{|c|}{12 - 18 years old, $n(\%)$} \\
\hline & $\begin{array}{l}2002 \\
\text { to } 2010\end{array}$ & $\begin{array}{l}2011 \\
\text { to } 2020\end{array}$ & $\begin{array}{l}P \\
\text { value }\end{array}$ & $\begin{array}{l}2002 \\
\text { to } 2010\end{array}$ & $\begin{array}{l}2011 \\
\text { to } 2020\end{array}$ & $P$ value \\
\hline LN (139) & $\begin{array}{l}12 \\
(21.4)\end{array}$ & $\begin{array}{l}12 \\
(15.4)\end{array}$ & 0.372 & $\begin{array}{l}27 \\
(55.1)\end{array}$ & $88(56.4)$ & 0.873 \\
\hline MCD (61) & $\begin{array}{l}16 \\
(28.6)\end{array}$ & $\begin{array}{l}18 \\
(23.1)\end{array}$ & 0.474 & $\begin{array}{l}11 \\
(22.4)\end{array}$ & $16(10.3)$ & 0.181 \\
\hline $\operatorname{lgAN}(34)$ & $7(12.5)$ & $7(9.0)$ & 0.514 & $6(12.2)$ & $14(9.0)$ & 0.503 \\
\hline FSGS (27) & $4(7.1)$ & $\begin{array}{l}10 \\
(12.8)\end{array}$ & 0.293 & $3(6.1)$ & $10(6.4)$ & 0.943 \\
\hline HSPN (7) & $2(3.6)$ & $1(1.3)$ & 0.381 & $0(0)$ & $4(2.6)$ & 0.260 \\
\hline APSGN (5) & $5(8.9)$ & $0(0)$ & $0.007^{*}$ & $0(0)$ & $0(0)$ & - \\
\hline ANCA-associated GN (4) & $2(3.6)$ & $2(2.6)$ & 0.738 & $0(0)$ & $0(0)$ & - \\
\hline TMA (4) & $0(0)$ & $2(2.6)$ & 0.230 & $0(0)$ & $2(1.3)$ & 0.428 \\
\hline TID (28) & $2(3.6)$ & $\begin{array}{l}13 \\
(16.7)\end{array}$ & 0.082 & $1(2.0)$ & $12(7.7)$ & 0.158 \\
\hline Hereditary diseases (8) ${ }^{\ddagger}$ & $3(5.4)$ & $2(2.6)$ & 0.404 & $0(0)$ & $3(1.9)$ & 0.331 \\
\hline Other diseases (5) $¥$ & $0(0)$ & $2(2.6)$ & 0.230 & $1(2.0)$ & $2(1.3)$ & 0.701 \\
\hline $\begin{array}{l}\text { Insufficiency for diagnosis } \\
\text { (17) }\end{array}$ & $3(5.4)$ & $9(11.5)$ & 0.219 & $0(0)$ & $5(3.2)$ & 0.206 \\
\hline Total (339) & $56(100)$ & $78(100)$ & & $49(100)$ & $\begin{array}{l}156 \\
(100)\end{array}$ & \\
\hline \multicolumn{7}{|l|}{${ }^{*} P$ value $<0.05$} \\
\hline \multicolumn{7}{|c|}{$\begin{array}{l}\text { ₹ Hereditary disease includes thin basement membrane disease, Alport syndrome, autosomal } \\
\text { recessive polycystic kidney disease and papillorenal syndrome (renal coloboma syndrome) }\end{array}$} \\
\hline
\end{tabular}

\section{Discussion}


In this 18-year retrospective study of pediatric renal biopsies, LN, MCD-related INS and primary IgAN remained the leading causes of pediatric kidney diseases in northern Taiwan [1]. Besides, we also discovered no significant changes in the histological patterns of pediatric kidney disease during the study period from 2002 to 2020 .

In our cohort study, more than one third of biopsied cases were lupus patients, especially older children and adolescents, and the most common biopsy-proven pediatric kidney disease was proliferative LN. A considerable number of studies already uncover Asian SLE patients had higher frequency of nephritis than Caucasians SLE patients (50\% - 60\% vs. 30\% - 38\%) [13, 14]. Moreover, childhood-onset SLE exhibits more aggressive disease course and higher disease activity than adult-onset SLE, leading to morbidity, mortality and irreversible damage in major organs especially the kidneys, brain and blood systems [15]. In a 20-year retrospective Taiwanese study of childhood-onset SLE cases, approximately $60 \%$ of pediatric lupus patients had LN at the time of initial presentation, and class IV LN was the most prevalent histological subtype in more than half of the pediatric lupus patients at onset [16]. The same disease spectrum of pediatric lupus was also found in Southeast Asian countries, displaying proliferative LN was the most common histological diagnosis and more severe compared with western cohorts [17]. Significantly, SLE-related GN is an important etiology of pediatric CKD in Asia.

Regarding primary glomerular disease, MCD has been the most prevalent pathology of INS among Taiwanese children and adolescents, and is more frequent in young boys than in girls. In our cohort, PRBs were performed in 77 pediatric patients with INS, and nearly half of them (40/77) were older than 10 years old for the reason that numerous studies suggested adolescent-onset INS had distinct clinical and histopathological features from early childhood INS. Eventually, our result found over the past two decades, MCD accounted for most teenage INS patients and only 14 pediatric patients aged 12-18 years were diagnosed of non-MCD pathologies (13 cases of FSGS and one case of IgM nephropathy). Besides, the estimated incidence of childhood INS was approximately $3.4 / 100,000$ children per year, and the male to female ratio was 1.83 in this study.

Primary IgAN was the third most common biopsy proven kidney disease in children and adolescents who had persistent asymptomatic hematuria in northern Taiwan. Similar to the previous studies, there was a relative predominance of males. IgAN is known the commonest primary GN worldwide, especially in Asia such as Japan, China, South Korea and Taiwan [18]. In Taiwan, massive urinary screening has been implemented in school-aged children since 1990 [19]. This policy facilitates early diagnosis and prompt intervention of children with kidney disease. Among our pediatric cases diagnosed of IgAN, almost all of them had excellent outcome and only one case who had renal function impairment at the time of diagnosis developed CKD.

Recently, increasing prevalence of idiopathic $\mathrm{MN}$ in pediatric and adult patients was reported in certain countries such as China and Singapore, which is suspected to be related to fine particulate air population $[5,9,20]$. On the other hand, our study showed the spectrum of biopsy-proven pediatric kidney disease unchanged in northern Taiwan, including no rising trend of MN. Looking back over past two decades on 
environmental and air pollution issues in Taiwan, leaded gasoline was banned since 2000 to reduce airborne lead exposure [10]. This is because chronic lead poisoning can impair intellectual development and renal function. In addition, multiple measures such as strict exhaust emission standards, Taiwan air quality monitoring network and increasing green spaces also benefit air quality maintenance and improvement here. Furthermore, after an antibiotic restriction policy for acute respiratory tract infection and comprehensive immunization program in Taiwan, there was a significant decline in infections with streptococcus pyogenes from 53.1 (1988-2000) to 10.7\% (2006-2010) as well as vaccine-preventable diseases. For instance, along with introduction of the 13-valent pneumococcal conjugate vaccine into the national childhood immunization program in March 2013, the incidence of invasive pneumococcal disease such as hemolytic uremic syndrome has dramatically declined [21]. Taken together, these policies are considered to be helpful for reducing the burden of infection-associated glomerular disease including APSGN $[22,23]$.

\section{Conclusion}

The effective public and environmental health interventions are beneficial for prevention and control of environmental risk factors and related illness including kidney disease. In this context, we speculated these measures might be partly responsible for unchanged pathological spectrum of pediatric kidney disease over the past two decades in northern Taiwan.

However, there are some limitations in this study. First, our research only assessed the cases from a single medical center. To clarify the changing spectrum of pediatric renal biopsies needs more sample cases from different hospitals and medical centers across the nation. Second, biopsy polices among different regions may affect the willingness and decision of this invasive procedure in clinical settings. Although the clinical indications of renal biopsies in pediatric population are generally based on KIDGO guidelines in our hospital, sample selection bias remains a challenge. In addition, our result reported a significant reduction of severe APSGN cases over the past decade. However, the incidence of mild form of APSGN is still uncertain among pediatric population in Taiwan.

\section{Abbreviations}

APSGN: Acute post-streptococcus glomerulonephritis; ANCA: Anti-neutrophil cytoplasmic antibody; CKD: Chronic kidney disease; FRNS: Frequent relapsing nephrotic syndrome

FSGS: Focal segmental glomerulosclerosis; GN: Glomerulonephritis; HSPN: Henoch-Schönlein purpura nephritis; INS: idiopathic nephrotic syndrome; IgAN: Immunoglobulin A nephropathy

LN: lupus nephritis; MCD: Minimal Change Disease; MN: Membrane nephropathy; PRB: Percutaneous renal biopsy; SLE: Systemic lupus erythematosus; SSNS: Steroid sensitive nephrotic syndrome; SRNS: Steroid-resistant nephrotic syndrome; SDNS: Steroid-dependent nephrotic syndrome; TMA: Thrombotic microangiopathy; TID: Tubulointerstitial disease. 


\section{Declarations}

\section{Ethics approval and consent to participate}

The study was approved by the Ethics Committee of Lin-Kou Chang Gung Memorial Hospital, Taoyuan, Taiwan (IRB approval number: 201900820A3, December 15, 2019). All procedures performed in studies involving human participants were in accordance with the ethical standards of the institutional and/or national research committee and with the 1964 Helsinki declaration and its later amendments or comparable ethical standards. All patients' guardians provided written informed consent.

\section{Consent for publication}

Not applicable.

\section{Availability of data and materials}

All data generated or analyzed during this study are included in this published article and its supplementary information files.

\section{Competing interests}

The authors have no conflicts of interest relevant to this article.

\section{Funding}

This research was funded by Lin-Kou Chang Gung Memorial Hospital, Taiwan (CMRPG3K0491).

\section{Authors' contribution}

MCY coordinated and conceived the study. CWY analyzed data and drafted the initial manuscript. CWY and TDC carried out the data collection. MCY and THY reviewed and revised the manuscript. All authors reviewed the results and approved the final version of the manuscript.

\section{Acknowledgments}

Not applicable.

\section{References}

1. Yu MC, Lee F, Huang WH, Hsueh S. Percutaneous ultrasound-guided renal biopsy in children: The need for renal biopsy in pediatric patients with persistent asymptomatic microscopic hematuria. Biomed J. 2014;37:391-7.

2. Imai $E$, Yamagata $K$, Iseki $K$, Iso $H$, Horio $M, M k i n o ~ H$, et al. Kidney disease screening program in Japan: history, outcome, and perspectives. Clin J Am Soc Nephrol. 2007;2:1360-6. 
3. Harambat J, van Stralen KJ, Kim JJ, Tizard EJ. Epidemiology of chronic kidney disease in children. Pediatr Nephrol. 2012;27:363-73.

4. O'Shaughnessy MM, Hogan SL, Thompson BD, Coppo R, Fogo AB, Jennette JC. Glomerular disease frequencies by race, sex and region: results from the International Kidney Biopsy Survey. Nephrol Dial Transplant. 2018;33:661-9.

5. Nie S, He W, Huang T, Liu D, Wang G, Geng J, et al. The Spectrum of Biopsy-Proven Glomerular Diseases among Children in China: A National, Cross-Sectional Survey. Clin J Am Soc Nephrol. 2018;13:1047-54.

6. Kopp JB, Anders HJ, Susztak K, Podestà MA, Remuzzi G, Hildebrandt F, et al. Podocytopathies. Nat Rev Dis Primers. 2020;6:68.

7. Harshman LA, Zepeda-Orozco D. Genetic Considerations in Pediatric Chronic Kidney Disease. J Pediatr Genet. 2016;5:43-50.

8. Obrador GT, Schultheiss UT, Kretzler M, Langham RG, Nangaku M, Pecoits-Filho R, et al. Genetic and environmental risk factors for chronic kidney disease. Kidney Int Suppl (2011). 2017;7:88-106.

9. Xu X, Wang G, Chen N, Lu T, Nie S, Xu G, et al. Long-Term Exposure to Air Pollution and Increased Risk of Membranous Nephropathy in China. J Am Soc Nephrol. 2016;27: 3739-46.

10. Huang PC, Su PH, Chen HY, Huang HB, Tsai JL, Huang HI, et al. Childhood blood lead levels and intellectual development after ban of leaded gasoline in Taiwan: a 9-year prospective study. Environ Int. 2012;40:88-96.

11. Yang HY, Chen PC, Wang JD. Chinese herbs containing aristolochic acid associated with renal failure and urothelial carcinoma: a review from epidemiologic observations to causal inference. Biomed Res Int. 2014;2014:569325.

12. KDIGO Clinical Practice Guideline for Glomerulonephritis 2012. Available at: https://kdigo.org/wpcontent/uploads/2017/02/KDIGO-2012-GN-Guideline-English.pdf. Accessed: 19 August 2021.

13. Yap DY, Chan TM. Lupus Nephritis in Asia: Clinical Features and Management. Kidney Dis (Basel). 2015;1:100-9.

14. Weening JJ, D'Agati VD, Schwartz MM, Seshan SV, Alpers CE, Appel GB, et al. The classification of glomerulonephritis in systemic lupus erythematosus revisited. Kidney Int. 2004;65:521-30.

15. Brunner HI, Gladman DD, Ibanez D, Urowitz MD, Silverman ED. Difference in disease features between childhood-onset and adult-onset systemic lupus erythematosus. Arthritis Rheum. 2008;58:556-62.

16. Lee PY, Yeh KW, Yao TC, Lee WI, Lin YJ, Huang JL. The outcome of patients with renal involvement in pediatric-onset systemic lupus erythematosus-a 20-year experience in Asia. Lupus. 2013;22:1534-40.

17. Tang SP, Lim SC, Arkachaisri T. Childhood-Onset Systemic Lupus Erythematosus: Southeast Asian Perspectives. J Clin Med. 2021;10:559.

18. Yeo SC, Goh SM, Barratt J. Is immunoglobulin A nephropathy different in different ethnic populations? Nephrology (Carlton). 2019;24:885-95. 
19. Lin CY, Sheng CC, Lin CC, Chen CH, Chou P. Mass urinary screening and follow-up for school children in Taiwan Province. Acta Paediatr Taiwan. 2001;42:134-40.

20. Woo KT, Chan CM, Lim C, Choo J, Chin YM, Teng EWL, et al. A Global Evolutionary Trend of the Frequency of Primary Glomerulonephritis over the Past Four Decades. Kidney Dis (Basel). 2019;5:247-58.

21. Wei SH, Chiang CS, Chen $\mathrm{CL}$, Chiu $\mathrm{CH}$. Pneumococcal disease and use of pneumococcal vaccines in Taiwan. Clin Exp Vaccine Res. 2015;4:121-9.

22. Worthing KA, Lacey JA, Price DJ, Mclntyre L, Steer AC, Tong SYC, et al. Systematic Review of Group A Streptococcal emm Types Associated with Acute Post-Streptococcal Glomerulonephritis. Am J Trop Med Hyg. 2019;100:1066-70.

23. Hibino S, Hoshino A, Fujii T, Abe Y, Watanabe S, Uemura O, et al. Post-streptococcal acute glomerulonephritis associated with pneumococcal infection. Pediatr Int. 2013;55:e136-8.

\section{Supplementary Files}

This is a list of supplementary files associated with this preprint. Click to download.

- SupplementaryFigure120220120.docx

- SupplementaryTable120220120.docx 